\title{
Construction and Implementation of the Flipped Classroom Teaching Mode of College English from the Perspective of Ecology
}

\author{
Jingjing Guan ${ }^{1, a}$ \\ ${ }^{1}$ Qiqihar Medical University, Qiqihar City, Heilongjiang Province, 161006, China
}

\begin{abstract}
Keywords: ecology; college English; flipped classroom; teaching mode; construction;
\end{abstract} implementation

\begin{abstract}
Classroom ecology regards English classroom as an ecosystem, and regards teachers and students as key elements of common development in a harmonious environment. With the development of information technology, flipped classroom, a new teaching mode, has entered our field of vision, and been carried out in full swing in China. In this paper, based on the author's learning and practical experience, we used the related theories of ecology to study the college English traditional classroom and flipped classroom to find the integration point of ecology and flipped classroom, and then analyzed the flipped classroom from the perspective of ecology. Finally, the ecological construction was conducted on the flipped classroom teaching mode.
\end{abstract}

\section{Introduction}

Most of the current research on flipped classroom focuses on the technical and static mode construction patterns, and lacks the analysis of dynamic interaction relationships among the key system elements, which not only is not conducive to the overall construction of the technical environment, but also affects the sustainable development of the flipped classroom. The analysis of the flipped classroom teaching mode from the perspective of ecology is helpful for researchers and practitioners to further understand the essential meaning of this new teaching idea, and systematically and accurately grasp the relationships among the key elements, which has a certain guiding significance for solving the problems encountered in teaching process. With the extensive application of modern educational information technology, the maturity of network environments such as cloud computing, cloud space, mobile APP, micro course, micro-film, mobile terminal and 4G flow provides a favorable technical support for introducing flipped classroom teaching mode and creating a college English learning environment based on ecology, which has become an important content and scientific research topic of college English innovation teaching reform in recent years.

\section{The Structure of the Teaching Ecosystem}

Ecosystem refers to an interactive and interdependent unified entity among the biological components and between the biology and non-biology in a certain time and space through continuous material circulation and energy flow. In the ecosystem, the ecological elements affect each other, and coordinate with each other to maintain the dynamic development and balance of the ecosystem. Ecology provides a scientific way of thinking that encourages people to study the various factors of educational ecology in a systematic view, holistic view, dynamic view and equilibrium view, and thus establishes an open, harmonious and sustainable educational ecosystem. Teaching activities including the teaching ecological subjects and ecological environment can be considered as a micro-education ecosystem. The ecological subjects include teachers and students. The ecological environment is a complex ecological environment including physical environment, social environment and standard environment (Figure 1). Physical environment refers to the materialized environment including physical space and information resources, which provides learning for the students such as classroom lighting, decoration, multimedia equipment, etc. Social environment refers to the relationship environment formed among the learners or between the learner and other groups in the process of learning launching such as the teacher-student relationship and student-student relationship in the process of teaching and learning. Standard environment refers to 
various attitudes, atmosphere and values in the process of learning, whose main manifestation is study style, learning norms and habits, and study mode. A benign teaching ecosystem should present a state of harmonious co-development and dynamic balance between teachers and students and among the ecological environment.

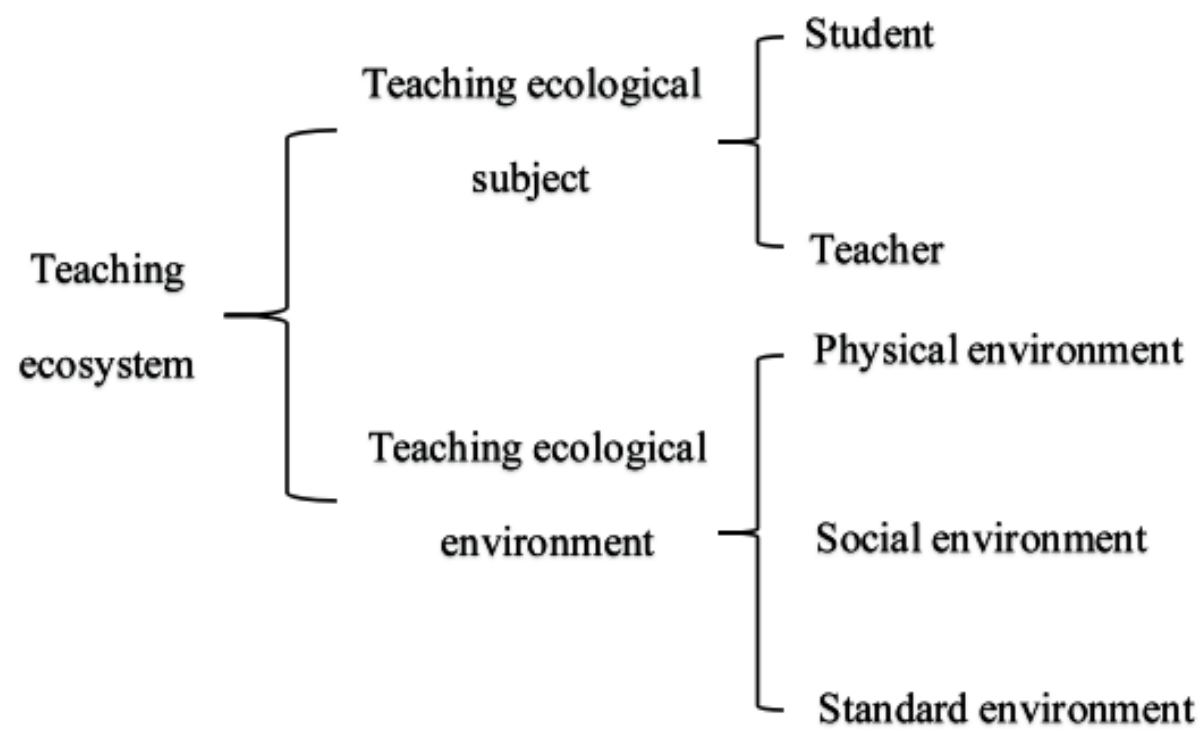

Figure 1 The structure of teaching ecosystem

\section{The Construction of College English Flipped Classroom Teaching Ecology}

The construction of the physical environment of flipped classroom ecology. First, the construction of the physical environment of the flipped classroom. The construction of the physical environment of the flipped classroom mainly refers to the optimization of social elements which make up the classroom ecological environment, including classroom arrangement, class size, seat layout and English teaching facilities. It is found that the classroom is conducive to cultivating two abilities of bilingual learners, namely comprehensive academic ability and reasoning ability. Classroom layout and English teaching facilities have a certain impact on students' psychology. Compared with the ordinary classroom without any English elements, the classroom with an English learning atmosphere is more interesting for the students to learn English, and makes them enter the English learning state quickly. English teaching facilities include computers for teaching, projectors, multimedia, network etc. which play an indispensable role in English classroom teaching. If they are appropriately and reasonably used in the teaching, the effectiveness of English teaching can be improved. The number of students in class has a large relationship with the effect of English classroom teaching, students' English language ability, and physical and mental development. In the class with small scale, each student can get the teacher's attention, has the chance of full participation in classroom activities, and has a higher probability of exercising their language skills and communication ability. Seat arrangement has a unique impact on classroom English communication activities and students' attitudes, behaviors and learning. Flexible seat arrangement facilitates the discussion among students, narrows the distance, and enhance the interaction between teachers and students and among students.

Second, the construction of language environment of flipped classroom. As we all know, the best way to master English is the combination of use and learning. However, for most students, the learning and use disconnect, the amount of learning language knowledge is large, and the chance of real use is little. Creating a classroom language-using environment requires the teachers creating a variety of "real" situation, and designing goals according to the classroom task. The first requirement is that the teachers should use the target language for teaching in the classroom, and the students should use the target language for communicating as much as possible. The second requirement is 
that English classroom should be regarded as the main place of learning and using English so that the target language knowledge can be used in time.

The construction of the main body relationship of flipped classroom ecology. First, the construction of trust relationship between teachers and students. The construction of good trust relationship between teachers and students includes not only the trust of the teachers on the students, but also the trust of the students on the teachers. On the one hand, the teachers should believe in students' ability, and make the students boldly try and practice. On the other hand, the teachers should continue to study, update their knowledge and teaching philosophy, enhance their overall quality, and win students' respect via excellent teaching ability and personality charm. The trust of the students on the teachers generated psychologically is conducive to the formation of a positive attitude towards learning, the stimulation of the enthusiasm of English learning and the smooth development of classroom teaching activities.

Second, the construction of collaboration relationship among the students. In English flipped classroom, the students should not be treated as isolated individuals, but important factors in classroom ecosystem. Every student communicates and feedbacks with their neighboring classmates. Guaranteeing the smooth information exchange channels among the students and developing a cooperative learning style is the key to promote the balance of English classroom ecosystem, and also in line with the objective requirements of English learning. English learning should not only master the knowledge-based contents such as the voice, intonation, vocabulary and grammar, but also learn to apply them in reality. Learning to use language is the ultimate goal of English learning. Therefore, the purpose of the establishment of a good teamwork relationship among the students and a learning mechanism of consolidating and using language knowledge is to enable the students to use language in language learning, and improve the language application ability in language use.

The construction of teaching methods of flipped classroom. First, respect for students' individual difference. Students' English level in the same class cannot be exactly the same. Therefore, the use of "one size fits all" teaching methods do not meet the actual situation. The teachers should teach according to students' ability, and put forward different objectives and tasks.

Second, advocate "three combination" mode. "Three combination" is the combination of teachers' guidance with students' main body, individual training with group activities, and language input with output. It is necessary to combine teachers' guidance with students' main body. The reason is that the students are the main body of English learning, and the task of learning must be done by the learners themselves. At the same time, the learners' knowledge limitations and the lack of learning autonomy need teachers' guidance and supervision. For language learners, it is a prerequisite to improve the language level through their own efforts, and master the voice, grammar and vocabulary knowledge. From the internal mechanism of language learning, the English descriptive knowledge in the cognitive system must be constantly activated to achieve the degree of automation. In other words, English descriptive knowledge learning is only the beginning of the language learning process. The ultimate goal is the acquisition of English procedural knowledge, namely the automatic use of the learned knowledge. In the process of the development of the descriptive knowledge stage to the procedural knowledge stage, it is necessary to activate and strengthen the learned descriptive knowledge, and establish the organic connection between meaning and form. One of the most important ways to establish this connection is the training of the combination of language input with output.

The construction of teaching database of flipped classroom. English teaching database is the main resource for teachers to import the English into the students, which includes English textbooks, English video, English newspapers and magazines, and network resources. The textbook is closely related to the development of students' English language. In the new century, although the English textbooks have achieved diversification, many textbooks are similar, and are difficult to meet the needs of students at different levels. The co-existence of oral and written languages in some textbooks makes the students generate the misunderstanding that there is no differences between the oral and written languages, which buries some unnecessary risks for the proper use of English. Chinese students learn both oral and written language, but both of them are different in terms of 
words and expressions. These differences would better be reflected in English teaching materials, such as the annotation of the abbreviation of spoken vocabularies and phrases with high occurrence frequency, and vocabularies and expressions in the glossary which are limited to spoken or written use. In addition, the best material of spoken English should be derived from the real life. Such materials will be authentic and natural.

\section{Summary}

Flipped classroom can maximize the use of students' time, which attributes to improving students' learning efficiency, and exploring students' learning potential. Its purpose is to optimize classroom ecological factors, strengthen the relationship between ecological subject and object, create a harmonious ecological environment, and thus make the students grow in a relaxed and happy environment. However, the English flipped classroom teaching is a huge organizational system from the ecological point of view. In addition to the above factors, the involvement of information technology also poses a challenge to classroom ecosystems, and leads to some ecological imbalances. To this end, we should also constantly improve and maintain the ecological balance of English classroom through the information technology reform of teaching management, and the information design of teaching content.

\section{Acknowledgement}

Subject source: The 2016 Heilongjiang Educational Committee Planning Program

Subject name: The Construction and Effective Implementation of College English Flipped Classroom from the Perspective of Ecology

Project number: GJC1316018

\section{References}

[1] YANG Beiyi. The ecological construction of flipped classroom of college English in higher vocational education [J]. Contemporary Education Forum, 2016, (04): 106-112.

[2] LI Yanping. The construction of college English hierarchical teaching mode based on flipped classroom [J]. Global Education Outlook, 2015, (06): 113-119.

[3] WEI Dongxin. The strategies for college English teachers to deal with the flipped classroom [J]. Education Exploration, 2014, (12): 37-39.

[4] CUI Yanhui, WANG Yi. Flipped classroom and its application in college English teaching [J]. China Electrification Education, 2014, (11): 116-121.

[5] ZHOU Zhilian, LONG Xiang, ZHAO Ming. The key issues of flipped classroom in college English teaching [J]. Wuhan Metallurgical Management Cadre College, 2014, (03): 80-83.

[6] MIAO Xin, ZHANG Jing, ZHANG Huiyuan. Application of flipped classroom mode in college English teaching [J]. Journal of Kaifeng Institute of Education, 2014, (04): 92-93.

[7] WANG Sumin, ZHANG Lixin. The survey on the acceptance degree of college English learners on flipped classroom [J]. Modern Educational Technology, 2014, (03): 71-78. 